\title{
Historein
}

Vol 13 (2013)

Questions and Orientations in History during the last 20 years. Part 2

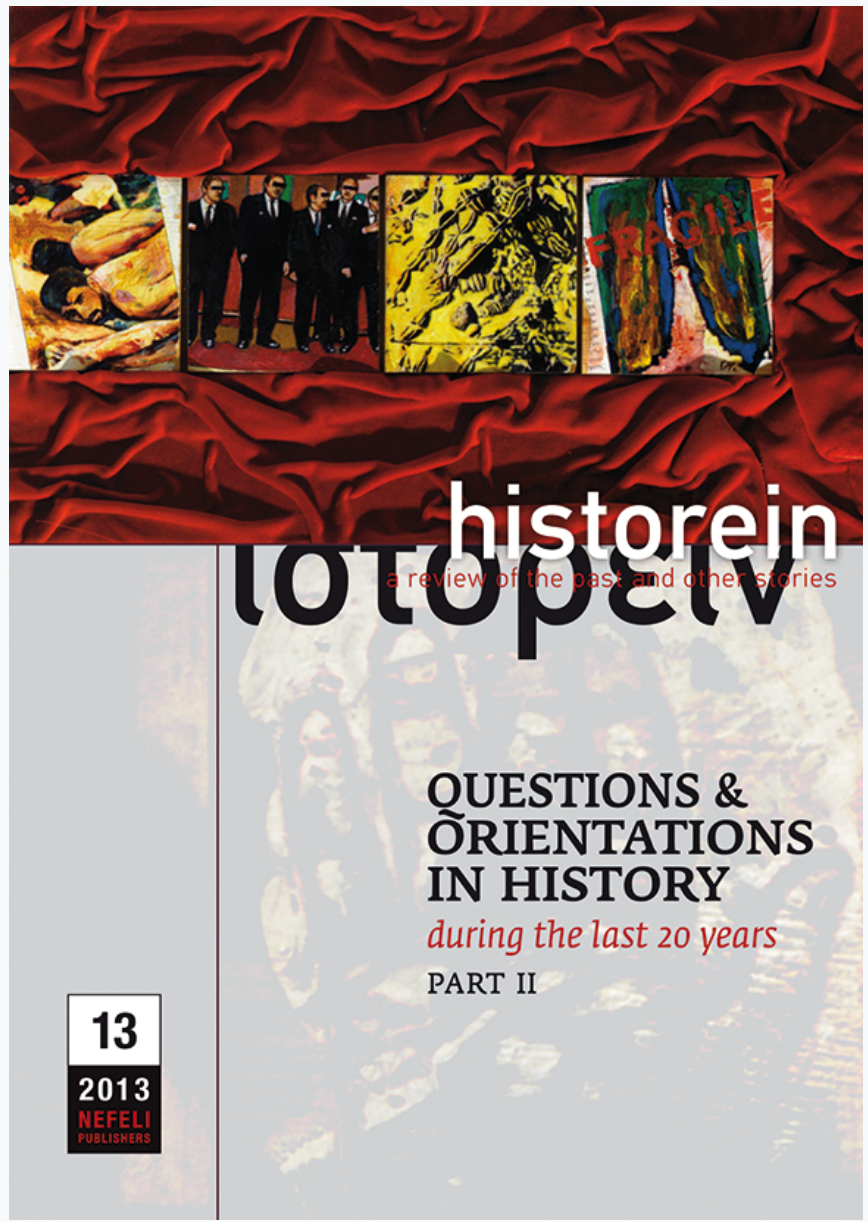

'Talkin' about a revolution, it sounds like a whisper': theories and debates on social revolutions

Polymeris Voglis

doi: $10.12681 /$ historein.170

Copyright @ 2014, Polymeris Voglis

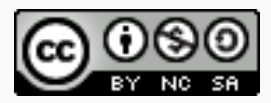

This work is licensed under a Creative Commons Attribution-NonCommercialShareAlike 4.0.

To cite this article:

Voglis, P. (2013). 'Talkin' about a revolution, it sounds like a whisper': theories and debates on social revolutions. Historein, 13, 47-56. https://doi.org/10.12681/historein.170 
Revolutions have always attracted the interest of scholars from several disciplines, such as history, sociology, political sciences or philosophy, for obvious reasons: the study of revolutions allows scholars to examine, explain and think about significant historical changes. The revolutions in France, Russia or China raise questions regarding the breakdown of political systems, economic models and social relations and the establishment of new societies. The study of revolutions has flourished since the 1960s, after the outbreak of anticolonial and revolutionary movements in the so-called third world, especially after the revolution in Cuba and the Vietnam war. Eventually, because these revolutions were contemporary, they were studied mostly by social and political scientists (rather than historians), who turned to the revolutions of the past (notably the French and Russian) in order to examine differences and construct explanatory comparative models. Thus, historians who wish to study theories of revolutions have to take into account a large body of literature from the social and political sciences.

This article reviews the literature on revolution in the social and political sciences and it is divided into two sections. In the first section, I will discuss the theories of revolutions that were developed from the 1960s to the 1980s. As I will show, from the 1990s onwards there have been significant changes in the study of revolutions, which I will address in the second section of this article. The disappointment with revolutions (especially after the Iranian revolution) and the collapse of the communist regimes in Europe played an important role in the reorientation of the discussion on revolutions. On the one hand, the study of revolutions as complex social and political phenomena was to a large extent re-

\section{'Talkin' about a}

revolution, it sounds

like a whisper':

theories and

debates on social

revolutions ${ }^{1}$

\section{Polymeris Voglis}

University of Thessaly 
placed by the study of civil wars, and violence became the prevalent analytical tool in the studies of revolutionary situations and civil wars, among political scientists in particular. On the other hand, revolutions became the subject of social movement theorists and, thus, they were studied from the revolutionary movements perspective rather than as successful sociopolitical transformations. For social movement and collective action theorists, revolutions should be studied within the larger framework of sociopolitical conflicts that also include protest movements, riots, uprisings, political violence and civil wars.

The first theoretical approaches on revolutions were developed on the grounds of the criticism of truisms regarding the causes of revolutions, some of which are very common even today, such as, for instance, that the increasing poverty and destitution of the population lead to revolutions or that revolutions occur in a specific phase of capitalist development when the relations of production inhibit the development of productive forces. Although a number of academic studies of revolution appeared as early as the 1920s in the United States, it was in the postwar era that these studies mushroomed. ${ }^{2}$ In the 1960s, new theories of revolution were put forward that focused on the changes and reactions that the introduction of capitalism brought to less-developed, agrarian countries. These studies did not address the question of revolution per se but studied revolution within the broader framework of the different "paths to modernity". One of the first and most important studies in that direction was the seminal study by Barrington Moore Jr entitled Social Origins of Dictatorship and Democracy. Adopting a comparative approach, Moore suggested that the "moment" of revolution was the period of transition to capitalist agriculture, when the relations between the social classes and the state were changing. Unsuccessful commercialisation of agriculture produced cleavages and conflicts between landowners and peasants that, under certain conditions (regarding the weakening of the ties between landowners and peasants, class differences among the peasants, the level of solidarity within peasant communities and the possibility of forming broader class alliances), could lead peasants to start a revolution. ${ }^{3}$ Two years later, another pathbreaking book, Samuel Huntington's Political Order in Changing Societies, was published. Huntington's main argument was that revolutions happen when traditional political structures and institutions fail to integrate or assimilate new groups that are mobilised into politics. The modernisation and industrialisation that accompany capitalism, the spread of education, the emergence of a working class and the impoverishment of peasants bring to the fore political forces and social groups that challenge the regime and demand participation in the political system. Political mobilisation, thus, destabilises a political system unwilling or unable to change. ${ }^{4}$

Eric Wolf's Peasant Wars of the Twentieth Century was in the same direction, i.e. the study of the impact of modernisation on traditional peasant societies, but offered an altogether different approach to revolutions. Whereas Moore and Huntington studied revolution as one possible outcome of modernisation (along with democracy, dictatorship and various types of "praetorianism"), Wolf focused exclusively on contemporary peasant revolutions. He argued that the introduction of capitalism in agriculture transformed peasants into market-oriented farmers and, as a consequence, traditional power mechanisms were questioned and the role of the elites in local communities as mediators between the peasant and the wider society was undermined. As traditional peasant society disintegrated under the impact of capitalism, the middle peasantry was radicalised and mobilised (and not the poor or the landless peasants who were dependent on big landowners for their 
livelihood). The middle peasantry became a political actor because it saw its position threatened by the advance of capitalism in agriculture, was independent of the landowners and had close ties with the cities, the hotbeds of radical ideas. Herein, Wolf argued, lies a crucial paradox: in his attempt to defend traditional ways from the changes that capitalism imposed, the middle peasant became a revolutionary. ${ }^{5}$

The study of revolutionary movements and politics was further developed by Charles Tilly, ${ }^{6}$ who focused on the political subjects by putting forward a theory of collective action, which can be viewed also as an early phase of his larger, life-time project on "contentious politics". According to Tilly, revolution is a conflict between (at least) two power blocs that claim to control the state by mobilising part of the populace. His analysis stresses the advent of capitalism, state-building and wars as the structural conditions for revolutions, but he is also interested in the subjective, historically specific conditions of the contenders for power. Therefore, he analyses revolution as a relation and a process: how discontent is transformed into mobilisation and then into an organised bid for power in a situation where control of the state and political legitimacy is contested. In a revolutionary situation, the two power blocs advance mutually exclusive claims for political power and its outcome is dependent on the ability of the contenders to mobilise people and resources.

In the late 1970s Theda Skocpol published a study on revolutions that remains the most influential in the field. In States and Social Revolutions, she proposed a structuralist approach to revolutions, which was radically different from the works mentioned above. Her analysis did not focus on the revolutionary subject (its goals, organisation or ideology) but on the "structural" relations and objective conditions, i.e. class relations, the state and the international context. At the heart of her analysis is the thesis on the potential autonomy of the state. Against the prevalent idea that the development of revolutionary movements may cause a crisis of the state, she argued the opposite, namely that the crisis of the state is the precondition for the emergence of revolutionary movements. More specifically, she argued that revolutionary crises occurred "when the old-regimes states became unable to meet the challenges of evolving international situations ... [a]nd they were constrained or checked in their responses by the institutionalised relationships of the autocratic state organisations to the landed upper classes and the agrarian economies". "Under such historical conditions, she continues, state authority, and the army in particular, falls apart, creating opportunities for revolutionary movements to overthrow the regime. Skocpol's seminal study has become a classic in the theoretical discussion of revolutions, as well as in the social sciences in general, in the United States because it marked a turn to the systematic study of the state (what sociologists at the time called "bringing the state back in").

While these studies, Skocpol's in particular, set the framework of the debates and theoretical discussions on revolution in the 1980s, since the 1990s there have been developments in new directions. As it is often the case, the starting point was the flaws in the theoretical approaches that had been advanced. The most interesting debate concerned Skocpol's study and it was more generally related to the critique of the so-called "second wave" of American sociologists. The critique concerned three aspects of her work: first, the comparative-historical method (sociologists criticised Skocpol for not being theoretical and abstract enough, while historians maintained that the search for general models pulverised the particularities of each case); second, her structuralist approach, 
which did not take agency into account in explaining revolutions; and, last, that by putting the emphasis on class relations and modes of production she overlooked the role of culture. ${ }^{8}$

At the same time in the 1990s, there was a significant shift in the study of revolutions as they became more and more connected with civil wars and the question of violence. For a number of scholars, mainly political scientists, violence became the vantage (and for some the sole) point for the study of revolutions. This shift was interrelated with broader historical and political changes. First, after the end of the cold war, the number of wars, and of civil wars in particular, increased dramatically. The outbreak of the civil war in Yugoslavia (the first war on the continent since 1945), the wars in the former Soviet republics, the proliferation of wars in Africa, as well as the discussion on "ethnic cleansing", put the question of violence high on the agenda of public and academic discussion. Second, the collapse of the communist regimes in 1989 challenged leftist ideas and expectations. To begin with, the collapse of the Eastern bloc was a theoretical challenge for students of revolutions. Did 1989 represent a type of revolution, and more to the point, a new type of revolution since it was not marked by the use of violence, a common characteristic of all revolutions until then? Moreover, and most importantly, the collapse of communist regimes dramatically changed the ideological and intellectual environment. The disappointment stemming from the failure of "real-existing socialism" (and even before that, the terrible outcome of the Iranian revolution) cast a new, unfavourable light on the idea (and expectations) of revolution. As it became increasingly associated with violence and repression, the concept of revolution acquired only negative connotations. Even the French revolution did not escape from this intellectual trend as Jacobinism was more or less regarded as the harbinger of the Soviet gulag.?

The shift from the study of revolutions to the study of civil wars highlighted a crucial problem: it identifies revolutions with civil wars. Most social revolutions at one point or another were causally related to civil wars (for instance in Russia, China or Nicaragua). However, the opposite is also true as many civil wars were caused not by a revolutionary change in society but a violent power conflict between two rival groups which had no interest in social of political change (for instance in Rwanda, Sierra Leone or Iraq after the fall of Saddam Hussein). The identification of revolution with civil war led scholars to downplay the specific political, ideological and cultural characteristics of revolutionary movements; violent conflicts during revolutions were stripped of any ideological and political content and were associated with strategies of domination and tactics of warfare. At the same time, the study of violence opened new areas of research. Social and political scientists moved away from the study of the causes of revolutions and civil wars to the ways they were conducted, and to the characteristics and the tactics of the power contenders in a violent conflict. Instead of a static view of classes and the state that the structuralist approach assumed, scholars suggested a more dynamic approach in their explanation of social revolutions, taking into account the impact of events, specific circumstances and contingency; some scholars sought to combine macrohistorical comparative analyses with field research at the microlevel; violence was no longer regarded as a simple consequence of civil war or revolution but the different forms of violence were explained by the intentions and composition of the belligerents.

In the last decade a large part of the literature on civil wars and revolutions has come from the political sciences and follows the rational choice theory. Stathis Kalyvas, in his book The Logic of 
Violence in Civil War, examines the instrumental use of violence in civil wars, namely violence as a means of control and coercion of the population by the conflicting parties. The support of the population either for the insurgents or the government is not dependent on class interests, political beliefs or cultural backgrounds but rather on the level of control that each side exerts over the population. The higher and more permanent the control, the greater the degree of support and collaboration, and therefore, less violence is used. On the contrary, in contested areas the conflicting parties use violence in order to coerce the population to collaborate with them (by providing information, enlisting in the armed forces, etc). Accordingly different forms of violence are used: selective violence occurs when control is complete and the flow of information (from denouncers who consider it safe) allows for selective targeting; indiscriminate violence is used to generate civilian compliance when control is limited and, thus, collaboration (and the providing of information) unavailable. ${ }^{10} \mathrm{~A}$ similar theoretical model is used for resource mobilisation. Anthony Oberschall and Michael Seidman argue that in revolutionary situations, the conflicting parties use the control of food procurement to compel the civilian population and soldiers to support them. The winner in a revolution or civil war "is the side that uses coercion most intelligently and manipulates food shortage most efficiently"." In a similar vein, Jeremy Weinstein argues that the violence of insurgent groups in Uganda, Mozambique and Peru is to a large extent conditioned by economic resources. Individuals participate in a rebel group after estimating the costs and benefits and, therefore, the recruitment strategies of the rebel leaders are based on offering incentives for participation. Groups with access to economic resources offer material incentives to the individuals; these groups attract opportunists, lack disciplining mechanisms and use widespread violence against civilians. On the contrary, rebel groups without access to economic resources draw on "social endowments" to recruit individuals and use ethnic, religious or ideological ties to mobilise the populace; these groups attract committed individuals, develop mechanisms of discipline and control and employ violence selectively. ${ }^{12}$

These approaches have enriched the discussion on revolutions, by setting a number of variables that determine the development of revolutions and explain the different levels and types of violence. However, they also have drawbacks. The first is that these approaches assume that subjects are highly individualised, act rationally and are motivated by personal gain. Other factors that may determine individual behaviour and decisions such as culture, habitus, emotions or class are downplayed. Rational choice studies analyse the actions of the subject from the point of view of the modern, western, utilitarian idea of the self, rather than within the framework of non-western, traditional, rural societies where these movements occurred. ${ }^{13}$ The second drawback of these studies is that the subject "evaporates", because its actions are conditioned by the choices of the warring leaders. Revolutions and civil wars are ultimately caused by warlords and party leaders who coerce the populace to take part in a conflict and to choose sides. The action of the subject, that is the thousands of people who participate in revolutions and civil wars, is explained by and restricted to the intentions and purposes of a determined minority.

Other scholars of revolutions have followed different paths. Under the impact of the "cultural turn" in the social sciences and in an attempt to overcome the dichotomy between structure and agency that dominated earlier studies of revolution, a number of political scientists and sociologists reinvigorated the study of revolution. Many studies turned to the question of agency in revolutionary 
movements and focused on values, ideas and emotions as explanatory factors for popular mobilisation. A good example of this new approach was Elisabeth Wood's study of FMLN guerrillas in El Salvador. Wood sought to explain the population's support for the guerrillas in the context of high risk. She overcame the limitations of the rational choice approach by focusing on the emotions and values of the peasants and the changes in political culture that the guerrilla groups brought about. To cite just one example of the role that emotions can play, Wood argues that one of the reasons for peasant participation in the insurgent activities was the "pleasure in agency", that is "the positive affect associated with self-determination, autonomy, self-esteem, efficacy, and pride that come from the successful assertion of intention". ${ }^{14}$ The role of emotions in revolutionary activism is highlighted by other scholars too. Michael Kimmel, in his theoretical treatise of revolution, identifies two emotions as primary sources of popular motivation to participate in a revolution: the combination of despair and hope. ${ }^{15} \mathrm{~A}$ more nuanced analysis of the role of emotions is offered by JeanPierre Reed, who, using the development of the FSLN movement in Nicaragua in the 1970s as a case-study, suggests that certain events provoke emotional responses that create the necessary context for the making of a successful revolution. These emotions are, on the one hand, the moral outrage at state-driven events that delegitimise the government (like arbitrary repression), and, on the other, the hope generated by the successes of the revolutionary movement which make a future popular victory and the overthrow of the regime credible..$^{16}$

A group of sociologists influenced by Skocpol and Tilly sought to combine structuralist/state-centred approach with collective action/social movement theories. At the one end of this group of scholars is Jeff Goodwin, who suggested a state-centred approach for the analysis of revolutionary movements. He argued that revolutionary movements were the result of violent and exclusionary state policies, and more specifically of a combination of unpopular economic policies, repression, indiscriminate violence, corrupt rule and weak policing capacities. While he acknowledged the limitations of the state-centred approach, namely the importance of factors such as organisational capability, resource mobilisation and the role of beliefs and emotions, he claimed that state practices are the most decisive element and the explanatory factor in the formation of revolutionary movements. ${ }^{17}$ Timothy Wickham-Crowley moved away from the state-centred approach by taking into account, on the one hand, the social structure and, on the other, the practices both of the governments and guerrillas to gain popular support. He argued that the Cuban and Nicaraguan revolutions were successful because the guerrillas managed to build up strong and sustained peasant support, maintain their military strength, and, most importantly, replaced the authority and legitimacy of the state by creating protostate institutions and providing the peasantry with various social services (health, education, local administration, etc). ${ }^{18} \mathrm{John}$ Foran suggested a multicausal theory of revolutions with an emphasis on the strategy of the movements. According to him, there are five interrelated factors that are necessary for a successful revolution: dependent development, a repressive state, a political culture of opposition, economic crisis and "world-systemic" disruption. Perhaps the most novel characteristic of his model was the "political cultures of opposition", a set of ideas and values that allowed people to make sense of their world and at the same time formed the basis of interclass alliances and revolutionary coalitions. "Political cultures of opposition," he writes, "may draw upon diverse sources: formal ideologies, folk traditions and popular idioms, ranging from ideas and feelings of nationalism (against control by outsiders), to socialism (equality and social justice), democracy (demands for participation and an end to dictatorship), or eman- 
cipatory religious appeals (resistance to evil and suffering)." ${ }^{19}$ The "political cultures of opposition" reflected the impact of the cultural turn on the social sciences. From this viewpoint, Foran's work, among others, is representative of the last generation in theories of revolution that pay particular attention to the cultural and subjective aspects of revolutionary movements. ${ }^{20}$

The most radical culturalist approach came from Eric Selbin. He claims that myth, memory and mimesis shape people's imaginary, help them to make sense of their world and are the driving forces of collective action for social change. Myth, memory and mimesis encoded in narratives, like stories, songs, fables, etc, transmitted from generation to generation and from one place or country to another, form people's consciousness and culture in their struggle against power. Selbin differentiates between four types of revolution stories: the civilising and democratising story, the social revolution story, the freedom and liberation story, and the "lost and forgotten" revolution story. Challenging the dichotomy between fact and fiction and focusing on the ideas and emotions of people, he examines narratives not simply as discursive representations or reconstructions but also as catalysts for collective action. ${ }^{21}$

In Greek historiography the concept of revolution is used mainly in the context of the Greek revolution of 1821. Unfortunately, the interest and research by historians on the revolution has been waning in recent decades. Nonetheless, the traditional nationalist historiography of the revolution has been heavily criticised and the few recent studies point to new areas of research on the topic, like the role of elites or local-ethnic aspects. Yet, a theoretical analysis of the Greek revolution in the broader, comparative perspective of the nineteenth-century national movements in the Balkans and elsewhere in Europe is still pending. ${ }^{22}$ In twentieth-century Greece, it may well be argued that the resistance during the occupation (1941-1944) and, certainly, the Greek civil war (1946-1949) were cases of revolution. The National Liberation Front (EAM) was first and foremost a national liberation movement, which was radicalised and initiated a process of social revolution in the countryside through the establishment of its authority and the introduction of social changes. During the civil war, the conflict between the two diametrically opposite camps (the Communist Party of Greece (KKE) and the Greek government) concerned the future social and political structure of the country; had the KKE prevailed in the civil war, a "people's democracy" would have been established in Greece. In these two different (yet connected) historical circumstances, there were attempts to establish a fundamentally different social and political system by means of mass mobilisation. What happened in Greece in the 1940s falls squarely into Skocpol's classic definition: "social revolutions are rapid, basic transformations of a society's state and class structures; and they are accompanied and in part carried through by class-based revolts from below". ${ }^{23}$ However, Greek historians have refrained from analysing the resistance and the civil war within the framework of a (failed) revolution. Among the few exceptions was Filippos lliou, who argued that the civil war in its "primary structure" was a social revolution. ${ }^{24}$ In general, the remarkable turn of Greek historiography in recent years to the study of the 1940s was not accompanied by any attempt to examine the Greek case within a broader theoretical framework or within a comparative perspective. As a consequence, the historiography and the public discussion on the 1940s to a large extent remains hemmed in by the question of who or what was responsible for the outbreak of the civil war: for some scholars, the rightwing terror gave the left "no other way out" but to resort to arms, while for others, the cause of the civil war is to be found in the Leninist ideology of the KKE. 
The 1940s remain a topic in which academic research and politics are inextricably related. Greek historians refrained from using the framework of revolution to analyse the 1940s because as a concept it was loaded and historically associated with catastrophe and disillusionment - that is, the tragic consequences of the civil war and the defeat of the KKE. Moreover, since the 1980s the revolutionary aspects of the resistance were silenced in the construction of a patriotic memory after the state's recognition of the "National Resistance". Having said that, one has to take into account the bigger picture. In recent decades the concept of revolution as a framework for the historical analysis of the 1940s appeared outdated because the political expectations of a radical transformation of Greek society has waned amid a growingly individualistic and consumerist society. Revolutions became something unthinkable and undesirable. The revolutionary narrative, as Noel Parker has brilliantly shown, was at first relocated from Europe to the periphery and then was transferred across national boundaries and imported back into Europe ("in a deceptive game of mirrors") until its collapse in the late twentieth century under the double impact of the ending of revolutionary movements in the periphery and the decline of the nation as a specific site for the role of the agent in revolution. ${ }^{25}$ These were the times of a conservative ideological backlash; revolution was delegitimised and was more or less identified with totalitarianism. A similar "displacement" of revolution can be seen to a certain extent in academia, as for some scholars the study of revolution was restricted to the study of the violence of revolutionary agents.

Yet, revolutions and revolutionary movements are complex social phenomena; they concern structures and agents, ideas and emotions, resources and availabilities, mechanisms and conjunctures. The literature on revolutions and revolutionary movements can be of great significance to the historiography of the Greek civil war by putting forward a synthetic framework of explanation and understanding. This frame of analysis can combine the study of state policies (the rapid postwar reconstruction of the state mechanism, the repression of leftists, the weak policing capacities in mountainous areas that allowed the guerrillas to grow, the dependence of a large part of the population on the distribution of relief and economic aid by the government, etc) with the development of a revolutionary movement (the tactics of irregular warfare, the dense organisational network, the different dynamics in the countryside and the cities, the mobilisation of disenfranchised groups, the lack of resources, etc) and the international context (the decisive intervention of Britain and the United States on the side of the government, the ambivalent attitude of the Soviet Union towards and the support of Yugoslavia for the Greek communists, cold war perceptions of the Greek situation, etc). Moreover, the literature of revolutions may enhance our understanding of the revolutionary subject, such as the commitment and discipline of the guerrillas, the familiarisation with the culture of armed struggle due to the resistance, the "ruralisation" of communist culture, the cult of heroism and self-sacrifice, etc.

In sum, revolution as a category of analysis, elaborated by social and political scientists in recent decades, has moved from the "whys" to the "hows", from structures to processes, from class to culture, and from a state-centred perspective to the study of revolutionary subjects. Some scholars use the comparative-historical method, others the microsocial; many political scientists adopted rational choice theory, whereas sociologists were influenced by the cultural turn and social movement theories. Thus, there is great diversity in the study of revolutions. It is noteworthy, however, that this literature, despite its richness and diversity, does not include the Greek civil war among 
the case studies. At the same time, scholars of the Greek civil war have not taken this literature into account. Nonetheless, I think that the category of revolution can be very helpful in the study and understanding of developments in Greece in the 1940s, and of the Greek civil war in particular, and the relevant literature can provide the necessary broader theoretical and comparative perspective. Perhaps the Greek civil war can also be a case for a new synthetic approach to revolutions.

\section{NOTES}

1 Lyrics from the song “Talkin' bout a revolution”, from Tracy Chapman's 1988 album, Tracy Chapman, Electra/Asylum Records.

2 For a history and discussion of the literature on revolutions, see Jack Goldstone (ed.), Revolutions: Theoretical, Comparative and Historical Studies, Belmont: Wardsworth, 2002.

3 Barrington Moore Jr, Social Origins of Dictatorship and Democracy, Boston: Beacon Press, 1966.

4 Samuel P. Huntington, Political Order in Changing Societies, New Haven and London: Yale UP, 1968, especially chapter 5 .

5 Eric R. Wolf, Peasant Wars of the Twentieth Century, New York: Harper and Row, 1969.

6 Charles Tilly, From Mobilization to Revolution, Reading: Addison-Wesley, 1978 and European Revolutions, 1492-1992, Oxford: Blackwell, 1993.

7 Theda Skocpol, States and Social Revolutions: A Comparative Analysis of France, Russia and China, Cambridge: Cambridge UP, 1979, 47.

8 See, for instance, Michael Burawoy, "Two Methods in Search of Science: Skocpol versus Trotsky", Theory and Society 18 (1989): 759-805: Edgar Kiser and Michael Hechter, "The Role of General Theory in Comparative-Historical Sociology", American Journal of Sociology 97/1 (1991): 1-30, William H. Sewell Jr, "Ideologies and Social Revolutions: Reflections on the French Case", The Journal of Modern History 57/1 (1985): 57-85; Farideh Farhi, “State Disintegration and Urban-Based Revolutionary Crisis: A Comparative Analysis of Iran and Nicaragua", Comparative Political Studies 21/2 (1988): 231-256; Elizabeth Nichols, "Skocpol on Revolutions: Comparative Analysis vs. Historical Conjuncture", in Richard Thomasson (ed.), Comparative Social Research, Greenwich: JAI Press, 1986, 163-186. See also John Foran (ed.), Theorizing Revolutions, London and New York: Routledge, 1997. Some of Skocpol's responses to this criticism can be found in her Social Revolutions in the Modern World, Cambridge: Cambridge UP, 1994.

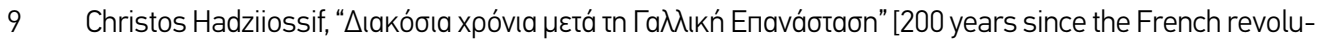
tion], Mnemon 13 (1991): 231-254.

10 Stathis N. Kalyvas, The Logic of Violence in Civil War, Cambridge: Cambridge UP, 2006.

11 Anthony Oberschall and Michael Seidman, "Food Coercion in Revolution and Civil War: Who Wins and How They Do It", Comparative Studies in Society and History 47/2 (2005): 375.

12 Jeremy Weinstein, Inside Rebellion: The Politics of Insurgent Violence, Cambridge: Cambridge UP, 2007.

13 Julia Adams, Elisabeth S. Clemens and Ann Shola Orloff, "Introduction: Social Theory, Modernity, and the Three Waves of Historical Sociology", in idem (eds), Remaking Modernity. Politics, History, and Sociology, Durham and London: Duke University Press, 2005, 1-72.

14 Elisabeth Jean Wood, Insurgent Collective Action and Civil War in El Salvador, Cambridge: Cambridge UP, 2003, 235 
15 Michael Kimmel, Revolution: A Sociological Interpretation, Cambridge: Polity Press, 1990.

16 Jean-Pierre Reed, "Emotions in Context: Revolutionary Accelerators, Hope, Moral Outrage, and Other Emotions in the Making of Nicaragua's Revolution", Theory and Society 33/6 (2004), 653-703. On the role of emotions in sociological analysis, see also Jeff Goodwin, James M. Jasper and Francesca Polletta (eds), Passionate Politics: Emotions and Social Movements, Chicago: Chicago UP, 2001

17 Jeff Goodwin, No Other Way Out: States and Revolutionary Movements, 1945-1991, Cambridge: Cambridge UP, 2001.

18 Timothy Wickham-Crowley, Guerillas and Revolution in Latin America: A Comparative Study of Insurgents and Regimes since 1956, Princeton: Princeton UP, 1992.

19 John Foran, Taking Power: On the Origins of Third World Revolutions, Cambridge: Cambridge UP, 2005, 21.

20 See, for instance, John Foran (ed.), The Future of Revolutions: Rethinking Radical Change in the Age of Globalization, London and New York: Zed, 2003; John Foran, David Stuart Lane and Andreja Zivkovic (eds), Revolution in the Making of the Modern World, New York: Routledge, 2008; Maria J. Saldaña-Portillo, The Revolutionary Imagination in the Americas in the Age of Development, Durham: Duke UP, 2003; J.E. Davis (ed.), Stories of Change: Narrative and Social Movements, Albany: SUNY Press, 2002; Frederick Corney, Telling October: Memory and the Making of October Revolution, Ithaca: Cornell UP, 2004.

21 Eric Selbin, Revolution, Rebellion, Resistance: The Power of Story, London and New York: Zed, 2010.

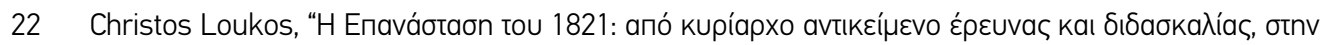

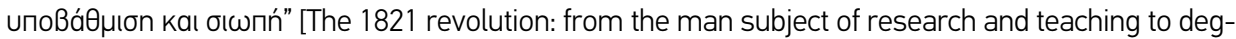

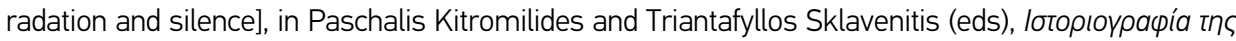

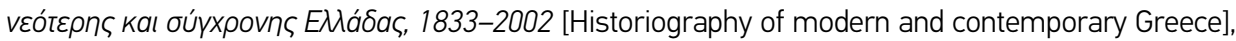
Centre for Neohellenic Research-National Research Centre: Athens, 2004, 579-594. For one of the few

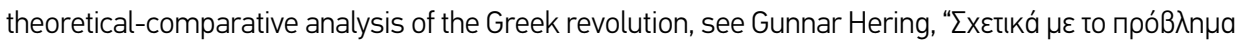

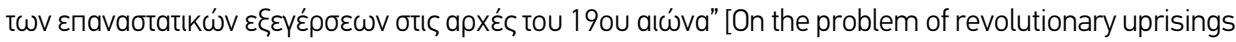
in the early 19th century], Ta Istorika 13/24-25 (1996), 105-120.

23 Skocpol, States and Social Revolutions, 4.

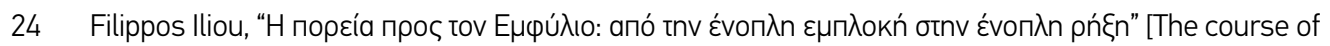
the civil war: from an armed imbroglio to an armed rupture], in llias Nikolakopoulos, Alkis Rigos and

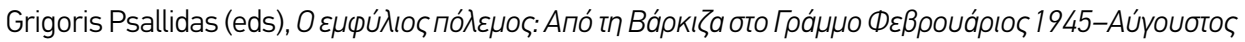
1949 [The civil war: from Varkiza to Grammos, February 1945-August 1949], Athens: Themelio, 2002, 25.

25 Noel Parker, Revolutions and History: An Essay in Interpretation, Cambridge: Polity, 1999, 134-159. 